\title{
8- Genealogia das imagens do Sertão Nordestino no cinema brasileiro: uma breve história
}

\author{
Diogo Cavalcanti Velasco ${ }^{1}$
}

\section{Resumo}

A partir de uma busca dos filmes que retratam o espaço nordestino no cinema nacional ao longo da cinematografia brasileira, propomos uma genealogia por meio de três momentos históricos: cinema brasileiro dos primórdios, o nordestern e o cinema novo com sua trindade seca e, por último, o cinema de retomada. Os signos forjados num contexto cultural da virada do século XIX para o XX (seca, messianismo, retirantes, entre outros) foram sendo ressignificados e chegaram a uma diversidade que condiz com a contemporaneidade.

Palavras chaves: Cinema brasileiro. Sertão nordestino. Cinema novo.

\begin{abstract}
Through a study with the history of the Brazilian movies that take place in Sertão Nordestino (Northeastern Countryside), we propose a genealogy by three different times: the beginning of the national cinematography, the "nordestern" and the new cinema with its "trindade seca" and, at last, the contemporarian movies. The signs forged in a cultural context in the turning point between $19^{\text {th }}$ and $20^{\text {th }}$ century (dry, messianism, retirantes, among others) were getting other meanings and got to a diversity that respects the contemporarity
\end{abstract}

Keywords: Brazilian cinema. Northeastern Sertão. New cinema.

\section{Resumen}

Empezando por una busqueda por películas que ponen el espacio nordestino del cine nacional junto a su cinematografia brasileña, proponemos una genealogia por médio de três momentos históricos: cine brasileños y sus primórdios, el "nordestern" y el cine nuevo com su trinidad seca y, por ultimo, el cine de retomada. Los signos forjados en el contexto cultural de la virada del siglo XIX para el XX (seca, messianismo, retirantes, entre otros) han sido resignificados e llegaran a una diversidad que condiz com la contemporanidad.

Palabras claves: Cine brasileño. Sertão nordestino. Cine nuevo.

\footnotetext{
${ }^{1}$ Possui graduação em Publicidade e Propaganda pela Universidade Federal de Goiás (2004); é mestre e doutor em Multimeios pela Universidade Estadual de Campinas (2010). Atualmente, atua como professor assistente na Universidade Federal de Sergipe (UFS).
} 


\section{Introdução}

Este artigo se propõe a colher as imagens cinematográficas nacionais que utilizam o Sertão Nordestino como local narrativo. A pesquisa basicamente foi estabelecida através de um levantamento fílmico e bibliográfico que pudessem dar luz às questões do problema de como esse espaço foi significado e ressignificado durante os ciclos cinematográficos do Brasil. O Sertão Nordestino se tornou um dos espaços, em conjunto com a favela, mais representativos dos filmes nacionais e sua trajetória fílmica diz muito sobre as epistemes de cada época, nos seus contextos políticos e culturais.

O cinema brasileiro nasceu na capital federal, Rio de Janeiro, em 1896. A imagem da Baía de Guanabara, de Afonso Segretto, trouxe o surgimento da representação espacial por um olhar metropolitano e "quase"2 moderno. Um registro seminal que dispararia a constituição das novas imagens do país, de uma nova visibilidade nacional neo-republicana. Uma construção imagética do novo Brasil que surgia com um cinema definitivamente Nacional ${ }^{3}$.

Nessa época, as imagens viriam a compor mais uma das formas de povoamento do imaginário da cultura metropolitana sobre os Brasis desconhecidos. Era um potencializador da invenção dos mesmos. A falta de interlocução entre espaços, dificultada por um baixo poder de deslocamento humano, trazia ao espectador as imagens de interpretação do Norte pelo ponto de vista do Sul. Como exemplo disso, em 1897 e 1898, fotografias foram expostas na capital sobre a Campanha de Canudos no Sertão baiano:

\footnotetext{
Campanha de Canudos

46 - Rua Gonçalves Dias - 46

Curiosidade! Assombro! Horror! Miséria!

Tudo representado ao vivo em tamanho natural por projeções elétricas hoje Cenas de toda a guerra de Canudos tiradas no campo de ação pelo fotógrafo expedicionário Flávio de Barros, por consenso do comandante em chefe das tropas.

Apresenta-se o verdadeiro e fiel retrato do fanático Conselheiro, fotografado por ordem do General Artur Oscar, a prisão do comandante das forcas fanáticas na Serra do Cambaio e o bravo $28^{\circ}$ de infantaria em cerrado fogo de artilharia contra os inimigos, 400 jagunços prisioneiros.

São apresentados 25 quadros.
}

\footnotetext{
${ }^{2}$ O Brasil nessa época começava a sua modernização. Podemos até utilizar a expressão "idéias fora do lugar" de Schwarz (1972) para o cinema, pois ele é característico de uma civilização moderna quando o vemos como um meio de comunicação de massas. O Brasil vivia um momento ainda pós-escravocrata e dominado por uma oligarquia rural.

${ }^{3}$ Enfatizo Nacional, pois o Brasil se desvencilhava definitivamente da colonização de Portugal no sentido de que a monarquia era descendente da família real portuguesa.
} 
As crianças nada pagam.

Entrada $1 \$ 000$ (ARAÙJO, 1976, p.40)

O primeiro aspecto que chama atenção é a chamada do anúncio: "Curiosidade! Assombro! Horror! Miséria!” Ele congrega duas ideias influentes na época: A falta de conhecimento do Norte pelo Sul brasileiro e a curiosidade do mesmo, antes dito apenas por veículos da oralidade e da escrita, e a reprodução de um elemento característico da dizibilidade acerca do Sertão nordestino: a miséria. O segundo aspecto é a utilização das fotografias como estratégia política do Sul ao tratar a Guerra de Canudos como obstáculo da sociedade para a civilização ("Horror!”). A comprovação de tal teor político pode ser evidenciada em julho de 1897 num anúncio da Gazeta de Notícias: "Realiza-se, hoje, conforme já noticiamos, na Inana, o benefício das viúvas e órfãos dos bravos que sucumbiram em Canudos, em defesa da República...” (in ARAÙJO, 1977, p.59). O terceiro aspecto é o "verdadeiro e fiel retrato do fanático Conselheiro", ícone nordestino, que depois seria reproduzido em diferentes formas no cinema nacional. Por último, a dimensão da liberdade da censura, o que não impediria o público infantil de ver a sessão, contribuiria para uma formação imagética do Norte já tendenciosa.

A composição imagética desses retratos é um exemplo de como o imaginário coletivo da metrópole já dava, precocemente, indícios da formação de estereótipos dos elementos de composição espacial do, até então Norte, com suas características principais de reprodução: a miséria e o fanatismo (banditismo e beatismo). Para confirmar isso, com o cinema, já em 1900, temos a projeção de uma das primeiras vistas de um imaginário sobre o Nordeste, mesmo que não em seu espaço, que pontua outra característica recorrente do Sertão Nordestino representado: a seca. O anúncio de vistas nacionais, que de acordo com Araújo (1977) eram as mais aplaudidas e tinha público, assim é escrito:

Foram ontem, em sessão especial dedicada a imprensa, inaugurada mais de
cem vistas, no cinematógrafo do Salão Paris no Rio.
Com a sala completamente cheia, às 7 horas da noite deu-se o começo à
exibição, sendo algumas das vistas aplaudidas pela sua nitidez, o que
acontece especialmente com as nacionais. Algumas são de fato muito
recentes, e entre essas notam-se as seguintes: Piquenique na Ilha do
Governador, O Bando Precatório para Seca do Ceará, A Passagem do enterro
do Dr. Ferrera de Araújo no largo do Machado, As Festas da Penha, O
Palácio do Catete.... (ARAÚJO, 1977, p.126)

A seca do Nordeste vai continuar sendo referencial imagético nas expedições do baiano Luiz Thomaz Reis, quando o mesmo registrou suas expedições em conjunto com 
o sertanista Cândido Mariano da Silva Rondon. Um dos encargos era vistoriar as obras contra a seca do Nordeste a partir de 1918. O objetivo, de acordo com Souza (1981), era utilizar as imagens e os filmes como forma de conhecimento da realidade, entretanto:

\begin{abstract}
A mediocridade do mundo cinematográfico brasileiro impediu, contudo, que seus filmes tivessem reconhecimento que mereciam. Os documentários de viagem que atingiram, com algum sucesso, os circuitos exibidores, continuavam repisando a exaltação ao berço esplêndido: "O Brasil Pitoresco", "O Brasil Maravilhoso", “O Brasil Grandioso” (SOUZA, 1981, p.33).
\end{abstract}

Diante de uma construção estereotipada do Sertão pelo Sul, a imagem autóctone, nascida no próprio espaço, teria a possibilidade de contribuir para essa desmistificação. Entretanto, o cinema no Brasil não se importava, em seus primórdios, em contribuir com a construção de uma imagem regional ou nacional que fosse. Nem mesmo o Estado via na projeção imagética a potencialidade da imagem para a construção de um EstadoNação. Nacional era ter uma película que fosse emulada dentro do território brasileiro, independente do objeto ou produção fílmica, nascia como negócio, consequência da era da mercantilização do entretenimento da vida moderna e se reproduzia como espetáculo de variedades, principalmente no eixo principal da nascente República, Rio de Janeiro e São Paulo. Dentro da história do cinema brasileiro, a pulverização da fatura cinematográfica aconteceu depois do arrefecimento da Bela Época (1908-1912), com os surtos regionais, período denominado por Souza (SOUZA, 1981) de Fase Artesanal do cinema brasileiro. Artesanal, pois se ensaiava uma produção organizada por meio de pioneiros do cinema.

\title{
1.1. O Sertão vai virar mar de mimetismos, "westerns" e Virgulinos
}

Como Marcelo Dídimo (2001, pg.22) afirma, o "ciclo" do cangaço é um marco na história do cinema brasileiro. Ele teria começado com filmes que abordavam a figura do cangaceiro nos anos 1920 e $30^{4}$, mas foi a partir do filme O Cangaceiro, de Lima Barreto (1953), que ele ganhou destaque aqui e fora do Brasil, onde conseguiu o

\footnotetext{
${ }^{4}$ Marcelo Dídimo fala de Filho sem mãe (Édson Chagas), Lampião, Fera do Nordeste (Guilherme Gaudio) e as imagens realizadas por Benjamim Abrahão em 1936 (filmagens encenadas de lampião e seu bando) que, inclusive, serão retomadas em dois filmes: no documentário Memórias do cangaço (Paulo Gil Soares, 1965) e Baile perfumado (Paulo Caldas e Lírio Ferreira, 199).
} 
primeiro prêmio internacional do país ${ }^{5}$. As imagens do suposto Sertão Nordestino, visto que a locação do filme foi no interior de São Paulo, foram pulverizadas. Sertão verde, aquoso, mas que, apesar disso, reproduzia um lugar "primitivo", reduzido a uma guerra de vendeta, de luta contra uma legislação civilizatória. Os cangaceiros, para o CentroSul, seriam os vilões da construção de uma nação civilizada, moderna, corroborando a ideia de que o Norte do Brasil representava uma ameaça para a integração do país.

A partir de então e, principalmente por causa da boa bilheteria do filme de Lima Barreto, os cangaceiros viraram fonte de renda e se reproduziram por mais de dez anos no que foi conhecido como o gênero do Nordestern no cinema nacional. Segundo Bernardet (1967), é com O Cangaceiro que se delineia as principais características dos outros filmes do ciclo que se formou. O termo Nordestern, cunhado por Salvyano Cavalcanti de Paiva, traduz em seu nome o gênero com o qual se assemelha, o Western americano. Falar dessa aproximação é condensar, nos dois, a forma como o espaço deixa de ter papel de ambientação para também se apresentar como personagem no imaginário do espectador.

O Western tem como características principais a representação de um espaço onde a lei ainda não tinha sido institucionalizada, o xerife, representante da força federal, não apresenta poder de mando, o lugar é extenso e árido, sem a riqueza de outras partes do país industrializado, as pessoas são embrutecidas, entre outras características. Para a passagem disso para o Sertão Nordestino, as analogias são fáceis de serem feitas. A luta das volantes contra o poder de mando do grupo lampianesco é clara perante a necessidade de impor um modelo civilizatório ao norte brasileiro. $\mathrm{O}$ lugar é pobre e necessita da extirpação desse tipo de rebeldia árida, justificada como consequência das circunstâncias locais. Nessa relação com o Western, até o papel da mulher como a que desperta sentimentos no herói é possível de ser evidenciado.

Sendo assim, como num Western nordestino, O Cangaceiro se situa na proposta de como se pensar, imageticamente, as fronteiras no Brasil. E pensar nelas como parte integrante de um todo peculiar nacional. Entretanto, como afirma Ismail Xavier, em sua análise do filme $O$ Cangaceiro, seria um misto de condenação moral e homenagem. A construção imagética-discursiva desse símbolo da cultura nordestina é apresentada como um produto da história sem volta, posto em uma época imprecisa, mas que já acabou. Ao mesmo tempo, existe um aspecto saudosista no filme, de homenagem, de

\footnotetext{
${ }^{5}$ Ganhou o prêmio de melhor filme de aventura e menção honrosa pela canção "Mulher Rendeira" no Festival de Cannes.
} 
exposição da cultura local sertaneja:

Declarado arcaico, o cangaceiro recebe um reconhecimento post-mortem. Tal como o índio, ele é redimido e homenageado como fator de nacionalidade no momento em que a tarefa do extermínio tornou sua presença menos efetiva e mais simbólica. Diante dele, a atitude do filme é assumir um tom de elegia. As imagens iniciais já nos instalam nesse terreno, trazendo a evocação sentimental de sua vida em campo aberto, de sua caminhada pelo sertão (XAVIER, 2007, p.52).

A grande preocupação a se pensar nesse deslocamento realizado pela construção da imagem do cangaceiro como descolado da história, como algo posto para memória local, estanque, é que ela caracteriza o local como arcaico e primitivo, diminuindo seus habitantes, a cultura sertaneja, que estão à espera da modernização. Tudo o que circunda o cangaceiro compõe o seu espaço. Manter uma época diegética imprecisa é universalizar o lugar que é construído pelo cinema. O Sertão como um espaço que ainda não foi despregado de Euclides da Cunha e sua concepção determinista. O cangaceiro é um determinado do espaço em que habita. Seu marginalismo, sua revolta anárquica pelos maus tratos com o camponês nordestino, é posto em cena na conjunção de aventuras que se seguem na narrativa. Ele é emanação do Sertão e dele nômade. Suas andanças descobrem o espaço sertanejo.

O ciclo do cangaço, com suas produções ulteriores a $O$ Cangaceiro, vai continuar reproduzindo esse sentido determinista e de varredura do espaço. O banditismo social virou um tipo de espetáculo a ser mercantilizado pelo cinema brasileiro. Cristalizados no gênero de aventura, esses filmes repisavam o espaço do Sertão como local hostil onde se configurava a luta pela honra com as próprias mãos. Citando brevemente alguns dos filmes, temos $O$ primo do cangaceiro (Mário Brasini,1955), A morte comanda o cangaço (Carlos Coimbra, 1960), Lampião, rei do cangaço (1963), Três cabras de Lampião (Aurélio Teixeira, 1962), Nordeste Sangrento (Wilson Silva, 1962), Entre o amor e o cangaço (Aurélio Teixeira, 1965), Quelé do Pajeú (Anselmo Duarte 1969), entre outros.

\subsection{O Sertão vai virar mar de revolução, utopia, maremoto social}

Nos anos 1960, o Sertão vira mar, de gente, de cinema. É por lá que se rivalizam cangaceiros e volantes, que retirantes vagueiam pelo deserto ruminando a fome, 
coronéis exploram seus trabalhadores, cantadores cegos caminham "cordelizando" uma estória. O espaço do Sertão profere a mise-en-scéne da revolta social, enraíza a cultura nordestina, amplia o olhar sobre o local que recrudesce politicamente, vira metonímia de um Brasil danado por suas condições sociais. Um mar de cineastas vai provocar maré alta no deserto árido sertanejo. Glauber Rocha, Nelson Pereira dos Santos, Roberto Santos, Ruy Guerra, Linduarte Noronha, entre outros, vão fazer do Sertão Nordestino personagem da história cinematográfica em um de seus momentos mais profícuos, o do Cinema Novo.

É nessa década que o bordão do espectador vai se formar: "Por que mostrar sempre a miséria? O Brasil não é apenas isso" (fala de um espectador de Aruanda, documentário de Linduarte Noronha que se passa no "deserto" nordestino) ${ }^{6}$. Por um tempo, o cinema do Brasil decidiu fazer isso, mostrar a miséria, assumir sua desgraça. E é claro que, como esse cinema era nacional, a experiência de ver a pauperização dos homens num espaço que lhe é comum, pois brasileiro, machuca a plateia. Como bem afirma Bernardet (1967, p.32), os olhos dos espectadores para o tratamento da realidade nacional é bem diferente dos mesmos que se voltam para o cinema estrangeiro, importado. Não é mero entretenimento. É uma máquina de fazer moer sentimentos mais profundos, pois é, de forma agradável ou não, uma má consciência do seu papel como habitante do país.

Essa é a revolta do espectador comum, burguês, que foi e vai ao cinema e não aceita essa miséria diegética. Ainda com o mesmo filme, Aruanda, Bernardet (1967) comenta a resposta de trabalhadores da construção civil, em sua maioria nordestinos, que tiveram um acolhimento melhor da fita:

\footnotetext{
Espectadores se levantaram, entusiasmados, para dizer que era preciso mostrar essa fita a todo mundo, aos que participavam das atividades do sindicato, e aos outros também. O entusiasmo foi exclusivamente motivado pelas sequências da cerâmica, por apresentarem técnicas que não são desenvolvidas no Sul. O que a fita pretendia dizer não fora comunicado (BERNARDET, 1967, p.39).
}

Isso condensa o pensamento de Bernardet acerca do Cinema Novo: os cinemanovistas faziam cinema para a cura da sua consciência, filmes realizados por uma classe média de esquerda para essa mesma classe, e não para o povo.

Nos congressos de cinema realizados no Brasil na década de 1950, a discussão se fazia pela busca de como o cinema brasileiro poderia desenvolver uma temática

\footnotetext{
${ }^{6}$ In BERNADET, 1967, p.39.
} 
nacional, voltada para a projeção, na tela, da realidade brasileira. Nelson Pereira assim afirmava:

\begin{abstract}
O "conteúdo" é fator preponderante para a aceitação do filme pelo público. As bilheterias dizem que o público brasileiro em primeiro lugar aprecia as histórias dos filmes brasileiros, pois ele fixa na tela sua vida, seus costumes. Se a produção cinematográfica seguir essa orientação nacionalista, ela simultaneamente satisfará os desejos do público e conquistará a totalidade do mercado (GALVÃO e BERNARDET, 1983, p.180).
\end{abstract}

Com a cinematografia brasileira dava-se ênfase para o que promovesse possibilidades de formação da identidade nacional. Entretanto, o Cinema Novo foi além. Não queria apenas mostrar a cultura popular, queria projetá-la e provocar a reflexividade do espectador. Era necessário comprometê-lo com o subdesenvolvimento do seu país. Deixava-se o repertório folclórico, compilação da cultura prosaica, para o questionamento dessa em seus sentidos humanistas, da práxis humana. Influenciados por uma postura de esquerda típica do nacionalismo da classe média da época, os cineastas queriam provocar um maremoto social. Que o "povo" se rebelasse, que criassem revolta. $\mathrm{O}$ cinema como expressão cultural, mas também de mudança, de desalienação popular.

Esse tratamento de uma realidade brasileira, tentativa de sociologização cinematográfica, consegue, no espaço do Sertão, sua concretização inicial. A classe média intelectual orgânica do cinema vai eleger o Sertão Nordestino como espaço metonímico para se falar do país. É a conjunção da miséria e cultura popular das mais representativas do espaço nacional que ganha projeção nos primeiros filmes do Cinema Novo. É um espaço de representificação do espectador, que tem a possibilidade de deixar o olhar descritivo, mimético, para o olhar crítico, para a ressignificação.

A relevância de tal espaço se torna completa com o passo a mais dado em conjunto com a tematização nacional pelo Cinema Novo, a construção de uma "linguagem nacional". Não era o bastante para a geração cinemanovista refletir, nas duas acepções do termo, o subdesenvolvimento do país apenas pelo conteúdo, mas também pela forma. A técnica também deveria ser nacional. E a conjunção desses dois fatores vai ser objetificada no documentário Aruanda, de Linduarte Noronha. O espaço a ser filmado: o Sertão Nordestino.

Assume-se o mal feito para dar cara a um cinema subdesenvolvido ${ }^{7}$ e que

\footnotetext{
${ }^{7}$ É importante ressaltar que essa maneira pela qual se busca um cinema que representa em si o subdesenvolvimento do país em seus processos e posicionamento político será formulada de uma forma mais radical pelo manifesto escrito por Glauber Rocha, Estética da Fome, em 1965.
} 
pudesse melhor retratar esse interior do Brasil, composto de seus "Sertões" e seus habitantes. A harmonia estava estabelecida entre "linguagem", locação, modo de vida e expressão cultural. Como afirma Fernão Ramos (1987, p.320), foram nesses primeiros anos da década de sessenta que o sol causticante do espaço sertanejo vai virar personagem do novo cinema. A conjunção entre o interior distante e a terra desértica e "ensolarada" torna-se locação para a narração de histórias de um "povo" de uma cultura própria, apesar da vida danada. Até a famosa busca pela "cor local" ou "luz local" característica da época, vai ser consagrada com o estourado do meio dia do Sertão, com a marcação forte dos contrastes dos filmes em preto e branco, com as sombras chapadas nos rostos dos habitantes, e na não utilização de filtros.

É importante ressaltar que o espaço sertanejo nordestino estava em seu auge de projeção nessa época. Depois da premiação de $O$ Cangaceiro no festival de Cannes, foi consagrado com o prêmio máximo da Palma de Ouro no mesmo festival, O Pagador de Promessas (Anselmo Duarte), em 1962. O filme narra a travessia de Zé do Burro e Rosa pelo Sertão em direção a cidade para pagar uma promessa a Iansã. Apesar do filme se concentrar na cidade, é o aspecto religioso fervoroso do protagonista que o constitui como um representante do interior do Nordeste. Essa imagem de um ser beatificado, com uma relação forte com a religião, será constantemente produzida e cristalizada como um dos traços da cultura nordestina. O filme, enquadrado-desenquadrado no movimento cinemanovista, não possui tão forte representação por se aproximar mais a um cinema narrativo clássico, diferentemente da proposta estética e política dos demais filmes produzidos posteriormente pelo Cinema Novo.

O Sertão se enche de ficção e "realidade". Fernão Ramos (1987, p.348), em sua classificação das trindades fílmicas para historicizar a escola cinemanovista, vai dar relevância, em sua primeira trindade, aos filmes ficcionais alocados em tal espaço. " $\mathrm{O}$ Nordeste seco e distante, do povo nordestino e sua condição de explorado" vai dar vazão às angústias dos cineastas da classe média nacionalista por meio de três filmes principais: Deus e o Diabo na Terra do Sol (Glauber Rocha, 1963), Os Fuzis (Ruy Guerra, 1963) e Vidas Secas (Nelson Pereira dos Santos, 1963). São três filmes de representação incontestável na história do cinema brasileiro. É deles grande quantidade de prêmios no exterior, grandes polêmicas, demarcações de linhas estético-políticas maduras e de transfiguração espacial (Sertão como metonímia para se falar de um Brasil). 


\subsection{O sertão virou mar - Aquosidade, liquidez e dilúvio de imagens}

Como promessa e profecia, o Sertão virou mar. Sertão-Mar que toca a baía de outros continentes. Tornou-se internacional. Internacional-popular, como diria Ortiz (1988). Foi inserido na dinâmica da globalização contemporânea, ou seja, se desterritorializou e foi reterritorializado. Faz parte, em artefato, da nação, da região e do mundo. Seus símbolos, tão densamente "sólidos", construídos com muito labor, foram liquefeitos. O Sertão ficou líquido. Dilúvio que inundou sua gente, suas ideias, suas coisas e suas imagens, colocando-as em constante movimento, em encaixe e desencaixe. A cada movimento, uma nova acomodação, se aproximando ora do "sólido", ora do "líquido" . Nessa contínua evaporação e condensação, o cinema nacional reencontrou o Sertão em sua contemporaneidade.

O Sertão já foi mundializado com a profusão de suas imagens. Sua memória se constituiu no processo de formação de estereótipos sobre ele. Contemporaneamente, no Sertão mundializado, esse sistema de símbolos que o representa faz parte do que Ortiz (1988) chama de cultura popular internacional. Somos lembrados por esse espaço e os signos que o constitui. "Os personagens, imagens, situações, veiculadas pela publicidade, histórias em quadrinhos, televisão, cinema, constituem substrato dessa memória"(ORTIZ, 1994, p.121). O risco dessa estereotipificação, movimento de repetição do encontro com o passado, pode gerar uma ideologia dominante do espaço. Ideologia que é produzida e reproduzida dentro e fora do país. O cinema da retomada, em suas produções comerciais, tem como uma de suas tendências, reproduzir este estereotipismo. O Sertão com as suas características da memória nos são lembrados de sua forma mais marcante dentro da história, com sua seca, miséria, seus sertanejos fortes, vivos, religiosos fervorosos. Não é por simples coincidência que filmes como Central do Brasil (Walter Salles, 1998) ou Eu Tu Eles (Andrucha Waddington, 2000), foram divulgados e conseguiram espaço nos mercados internacionais. Essa é sua maneira tradicionalista de representação. Reprodução de uma invenção já arquitetada pela história.

Entretanto, é justamente, na contra-face de um movimento globalizante que

\footnotetext{
${ }^{8}$ Utilizo os termos "sólido" e "líquido" entre aspas porque são categorias utilizadas por Bauman no livro Modernidade líquida (2000) para demarcar uma mudança histórica trazida pela modernidade contemporânea. Tudo que era "sólido" antes, que tinha formas estabelecidas, rigores e padrões, agora se liquefaz, tenta tomar corpo, ganhar forma, encontrar múltiplos discursos.
} 
reproduz estereótipos, que grupos subordinados se inventam a partir do que lhe é produzido por meio da cultura metropolitana dominante. Hall (2003) afirma que essa invenção ocorre pela transculturação, característica que justapõe representações de modos de cultura em uma rede de acesso mais difusa. A tradição e a tradução são combinadas de diversas formas. Novamente, temos uma memória, um passado, que se traduz de acordo com nossa época. Se choca em seus modos reificados e questionadores, subalternos.

Logo, a diversidade das obras produzidas no novo ciclo do cinema nacional garante a retomada histórica, mas não possibilita a cópia, visto que parte de uma nova configuração para se trabalhar o espaço. Interpenetram-se os tempos que traduzem na tela uma nova preocupação, o jogo entre o local e suas dimensões paralelas, o nacional e o global. Na era globalizante, o cinema, como meio artístico e de comunicação, traz à luz sua conjuntura, por mais particular e familiar que o objeto nos pareça:

\footnotetext{
Nossa relação com o mundo mudou. Antes, ela era local-local, agora ela é local-global. Assim, a individualidade de cada lugar é, a sua maneira, o mundo. Um elemento para a totalidade, sem perder a diferença no todo (IANNI, 1985, pg.252).
}

É ao encontro disso que Ismail Xavier (2001, p.48) vai caracterizar o cinema brasileiro da retomada como o conjunto de seu produto diverso. Como ele bem comenta, a diversidade é uma coisa que sempre existiu na história do cinema brasileiro, mas agora ela é característica principal, a protagonista do recomeço de produção. De forma mais geral, Bauman (2000) também comenta sobre o diverso contemporâneo: "a pluralidade sempre existiu, o que muda são as formas de lidar com essa pluralidade" (p.10). Sendo assim, o Sertão, em sua representação pelo cinema brasileiro diverso contemporâneo, também se tornou plural e diferentemente abordado.

Mas, nessa pluralidade, o cinema também é nacional, é da nação, e não só do mundo. A representação cinematográfica enraizada em suas culturas e espaços locais, nas diversas formas em que se encontram, são também localizadas, apesar de não serem desvinculadas do pertencimento global. É assim que Stuart Hall (1997) vai caracterizar esse sistema globalizante da diferença como uma com-formação. O que existe, então, é uma negociação, ora o recrudescimento do local, do nacional, ora manifestação do universal, global. No cinema, inclusive, a junção desses dois processos pode ser evidenciada dentro de um mesmo filme, como fragmentação de um todo, aspectos tanto do particularismo, como do universalismo. Enfim, esse processo de transformação do 
estranho, como denomina Bauman (2000) para o diferente, o marginal, o local, deixa de ser elemento pitoresco, exótico e medonho, regulamentado assim pelo Estado-Nação, para se tornar componente do processo de diferenciação maior. O mundo deixa de ser heterófobo, para se tornar heterofílico, sem perder, contudo, seu jogo de relações de poder. O espaço do Sertão Nordestino, antípoda da região metropolitana do Centro-Sul, foi sempre encarado como esse espaço marginal "estranho" no território brasileiro, que hoje se torna diferente, englobando esse encontro mundial com a heterofilia.

É dessa nova forma, com-formando esses elementos dos dois processos, que o cinema brasileiro ainda aborda o nacional e o local, que dentro do jogo globalizante, ainda garante o processo de heterogeneização do mundo atual. O espaço, então, percorre dois caminhos em suas manifestações representativas na mundialização. A primeira, com a desterritorialização, deixa o espaço vazio, abstrato, deslocalizado. A segunda, como o espaço é uma categoria social, é construído também por meio das convenções culturais humanas, tem de ser localizado.

Não é, despropositadamente, que o recomeço do cinema brasileiro tem como marca inicial o filme Carlota Joaquina (Carla Camurati, 1995) com apelo de localização nacional significativo. O processo de perda da relevância dos vínculos da Nação para os seus indivíduos pode se tornar corrente devido a desvinculação da mesma com o território (o mesmo se dá para região e espaços localizados), mas o sentimento de "pertença" construído historicamente por ela, ainda é parte orgânica dos mesmos. Seus habitantes entram no jogo globalizante de integração e fragmentação.

É dessa forma que a temática da identidade nacional e regional volta a ser um filão para ser abordado no cinema da retomada. Segundo Ismail Xavier (2000), ela é tratada de duas formas, uma como mercadoria e outro como problema. A forma mercadológica de se tratar os temas nacionais são as que visam tratar da identidade de uma maneira mais homogeneizante e pendendo para os signos que fazem potencializar o sentimento de pertença dos brasileiros. A outra maneira, que a vê como um problema, vem questionar ou refletir sobre essa identidade, colocando os novos problemas da atual conjuntura como parte integrante do filme. Em ambas, o espaço do Sertão é evidenciado como local privilegiado, seja em retomadas históricas ou com uma perspectiva mais contemporânea.

Desde que a retomada se tornou um marco para a cinematografia nacional, foram produzidos mais de 15 filmes alocados no Sertão Nordestino. Dentro da primeira linha, que trata o espaço como um local de memória para o país, estão filmes como 
Central do Brasil, Abril Despedaçado (Walter Salles, 1998), O auto da Compadecida, Lisbela e o Prisioneiro (Guel Arraes, 2000 e 2003), Eu tu eles (Andrucha Waddington, 2000), O caminho das Nuvens (Vicente Amorim, 2003), O homem que desafiou o diabo (Moacyr Góes, 2007) e A Máquina (João Falcão, 2006). Na outra, temos Narradores de Javé (Eliana Caffé, 2003), Baile Perfumado (Lírio Ferreira, 1997), Cinemas Aspirinas e Urubus (Marcelo Gomes, 2005), Árido Movie (Lírio Ferreira, 2005), Deserto Feliz (Paulo Caldas, 2007), O Céu de Suely (Karim ainouz, 2006), 2000 Nordestes (Vicente Amorim e David França Mendes, 2000), Sertão de Memórias (José Araújo, 1997) e $O$ Fim e o Princípio (Eduardo Coutinho, 2005).

Não se trata de fazer uma generalização estanque desses dois movimentos do cinema brasileiro sertanejo. É claro que, em alguns deles, é possível encontrar o saudosismo nordestino e a implicação contemporânea com o espaço. Apenas fizemos uma segmentação que mostra a tendência geral dos filmes com relação a formas de abordagem do Sertão.

\section{Referências}

ALBUQUERQUE, Durval Muniz Jr. A Invenção do Nordeste. São Paulo: Ed. Cortes, 1999.

ALMEIDA, Paulo Sérgio e BUTCHER, Pedro. Cinema Desenvolvimento e Mercado. Rio de Janeiro: Ed. Aeroplano, 2003.

ARAÚJO, Vicente de Paula. A Bela Época do Cinema Brasileiro. São Paulo: Editora Perspectiva S.A., 1976.

BERNARDET, Jean Claude. Brasil em Tempo de Cinema. São Paulo: Editora Paz e Terra, 1978.

BENTES, Ivana. Da estética à cosmética da fome. Jornal do Brasil, 08/07/2001.

GALVÃO, Maria Rita e BERNADET, Jean Claude. O Nacional e o Popular na Cultura Brasileira. São Paulo: Brasiliense, 1983.

GOMES, Paulo Emílio S. Cinema brasileiro: trajetória no subdesenvolvimento. Rio de Janeiro: Paz e Terra, 1986.

HALL, Stuart. Identidades Culturais na Pós-modernidade. Rio de Janeiro. Ed.DP\&A, 1997. 
IANNI, Octavio. Teorias da Globalização. Rio de Janeiro: Ed. Civilização Brasileira S.A., 1985.

MENEZES, Djacir. O Outro Nordeste. Rio de Janeiro: Livraria José Olympio Editora, 1937.

NAGIB, Lúcia. O Cinema da Retomada. São Paulo: Ed. 34 LTDA, 2002.

RAMOS, Fernão (org.). História do Cinema Brasileiro. São Paulo: Arte Editora Ltda, 1990.

RAMOS, José Mário Ortiz. Cinema, Estado e Lutas Culturais. Rio de Janeiro: Ed. Paz e Terra, 1983.

VIEIRIA, Marcelo Dídimo Souza. Filme de Cangaço: a representação do ciclo na década de noventa no cinema brasileiro. Campinas. Dissertação de Mestrado. Orientador Adilson José Ruiz. Unicamp, 2001.

XAVIER, Ismail.O Cinema Brasileiro dos anos 90. Praga, São Paulo, n.9, p.97-138, jun. 2000.

Sertão Mar. Rio de Janeiro: Editora Cosac\&Naify, 2007. 